\title{
Investigations of Non-Linear Viscoelastic Properties for Polypropylene/Clay-Nanocomposites through Melt Flow Birefringence and Damping Function
}

\author{
MARYAM Mudasir ${ }^{a},{ }^{,}$, RIAZ Ahmed ${ }^{\text {b }}$ \\ Department of Applied Chemistry and Chemical Technology, \\ University of Karachi, Karachi 75270, Pakistan \\ amaryam.mudasir@uok.edu.pk, ’ahmedriazku@yahoo.com
}

\begin{abstract}
Keywords: Polypropylene/clay-nanocomposites, Flow Birefringence, Damping Coefficient, Nonlinear Viscoelasticity, Principal Stress Difference
\end{abstract}

\begin{abstract}
Rheological investigations are reported for pure polypropylene and its clay-nanocomposites to establish viscoelastic properties and filler concentration relationship. Flow birefringence is performed through a slit-die to obtain centerline principal stress difference during extensional flow. The centerline stress profile of clay-nanocomposite revealed additional viscoelastic nature even at low silicate concentrations whereas no exceptional strain hardening was reported. Effects of higher filler concentrations were further examined during the simple shearing flow to consider non-linear viscoelasticity in terms of damping function. The increase in damping coefficient with increasing clay concentration showed that polymer-nanocomposites were more strain sensitive. The Wagner's exponential damping function adequately described the time-strain separability at all clay concentrations studied. The results of both investigations revealed that the polymers were time-strain separable at all clay concentrations studied during elongational and simple shearing flows, whereas the filler orientations were found to be different for different melt flow behavior.
\end{abstract}

\section{Introduction}

Polymer nanocomposites have been considerable for research and commercialization from many years [1-5]. Polymer-clay nanocomposites exhibit relatively superior mechanical and materials properties than those of pure polymers due to stronger polymer-clay interactions. The enhanced properties are achieved at very small clay concentration (up to $5 \mathrm{wt} . \%$ ) [6]. Their melt processing is important from rheological point of view as differences in melt flow properties of pure polymer and their clay nanocomposites could be possible due to grain structure, size and surface characteristics of the nano filler [7, 8]. Therefore understanding the melt flow properties of polymer layered silicate nanocomposites would help to understand the molecular orientations as well as their processibility.

The flow induced birefringence is important to consider extensional rheology using measurements of light interactions with the flowing material. The birefringence property of a flowing melt could be related to stress distributions which govern the melt flow behavior of polymer chains [9-11]. It was found that the ratio of birefringence $(n)$ and overall stress state $(\tau)$ under deformation was found to be independent of shear rate, polymer concentration, and chain length distribution over a wide range of these variables, resulting stress optical rule as [12]:

$$
\Delta \mathrm{n}=\mathrm{C} \Delta \tau
$$

Where $\mathrm{C}$ expresses the stress-optical coefficient. As the sample to be studied thorough flow birefringence must be transparent having proper optical properties [13], this technique has not been applied for polymer filled composites. Clay layers may affect system birefringence being highly anisotropic in comparison with bulk polymer chains. The melt induced birefringence study for polymer/clay-nanocomposites may be possible due to their good optical properties. A high optical transparency has been reported for polyvinyl alcohol/sodium montmorillonite clay nanocomposites up to 10 wt.\% clay concentration attributing to the comparable wavelength of visible light 
$(400-700 \mathrm{~nm})$ and lateral dimensions of clay $(50-1000 \mathrm{~nm})$ [14]. Hence molecular dispersions of the nano-filler could maintain the optical properties of polymer/clay-nanocomposites $[15,16]$. Other rheological investigations during extensional flow revealed strain hardening due to strong molecular interaction among the polymer, compatibilizer and the clay layers [17, 18]. Also the rheopectic behavior and strong strain hardening in polypropylene/clay nanocomposites melt during elongational flow was documented which is also confirmed by the transmission electron microscopy showing perpendicular arrangement of the clay layers to the stretching direction [19].

The rheological properties of polymer clay nanocomposites become strain sensitive during simple shearing flow resulting in nonlinear viscoelastic response even at moderate strains [20]. The chain orientations are dominated by the silicate layers according to the flow direction. The steady shear viscosity shows yield stress at low shear rate where pure polymers exhibit Newtonian behavior. Also shear thinning viscosity appears earlier that converges to pure polymer viscosity at high shear rates as a result of filler network break down and layer alignments parallel to the flow direction [21-23]. The damping function explains elastic behavior of polymers melt flow being stronger for less elastic polymers. The low density polyethylene shows reduced strain hardening by adding inorganic fillers (glass beads, glass flakes, talc, and glass fibers) attributed to the initial orientation of the fillers [24]. It is important to notice that the damping function depends more on filler concentration rather than on their size [25]. Hence at higher filler concentration, the damping function would be decreased, and nonlinear behavior would appear earlier at lower deformations [25]. Similarly effects of organo-smectite clay concentration has been demonstrated for poly methyl methacrylate nanocomposites [26]. The stress relaxation with respect to strain was sufficiently described using Papanastasiou damping function in a sigmoidal equation [27] for disordered styrene-1, 4-isoprene diblock copolymer and organo montmorillonite clay intercalated nanocomposites in the nonlinear viscoelastic region [28]. Here damping coefficient " $\alpha$ " increases with silicate concentration, therefore more strain softening was reported than the pure matrix. However at higher silicate percentages (6.7 and $9.5 \mathrm{wt}$ \% \%), a time-strain separable relaxation modulus could not be achieved due to the structural evolution even at modest strains.

In this study, first flow birefringence was used to study extensional rheology through abrupt entry flow for polypropylene/clay-nanocomposites and results were compared with step strain and steady shear rheology during simple shear to highlight differences in viscoelastic properties of a pure and its clay-nanocomposite. The non linear viscoelastic properties in terms of damping function was investigated considering an exponential dependence of damping function on strain as proposed by Wagner [29]. According to Wagner, the damping function could be expressed in an exponential form [29]:

$$
h\left(I_{1}, I_{2}\right)=e^{-k \sqrt{\beta I_{1}+(1-\beta) I_{2}-3}}
$$

where $\mathrm{k}$ and $\beta$ are the damping coefficients in simple shear and elongational flow, respectively. $I_{1}$ and $I_{2}$ are the first and second invariants in the Finger tensor, respectively. Investigations were carried out starting from smaller clay concentrations up to $2 \mathrm{wt} . \%$, as before the damping properties were studied for quiet higher amounts (up to $10 \mathrm{wt} . \%$ ) and time-strain separability issues were addressed [30]. Thus this study would improve the rheological understandings for melt flow behavior of pure polyolefins and their clay nanocomposites showing particularly effect of layers concentration and explain the basic differences within molecular orientations in presence and absence of highly anisotropic silicate layers through flow birefringence and damping function coefficient.

\section{Experimental}

Materials. The pure polypropylene (high melt flow index, MFI) and its clay nanocomposite under trade name 'CAP 101 PP Hi-Composite' were supplied by Asia Technology Pioneers, Tehran Iran. The clay nanocomposite was a homopolymer nanocomposite of injection molding grade which was commercially synthesized by melt compounding of polypropylene with $1 \%$ by weight 
polypropylene grafted maleic anhydride (PP-g-MAH) as compatibilizer and 'Cloisite 15A' (up to 3 wt.\%-4 wt.\%) as reported by suppliers. The clay modifier concentration was 125 meq /100 gm clay. The clay content of CAP 101 was determined by heating a known mass of the sample in a furnace at $700^{\circ} \mathrm{C}$ for 3 hours. The total clay content was found to be $1.783 \mathrm{wt} . \%$. With loss on ignition for Cloisite 15A [31] CAP-101 will be considered as $2 \%$ clay nanocomposite. Two more samples were prepared by diluting CAP-101 nanocomposite with its host pure polypropylene. A significant dispersion was attained by using co-rotating twin extruder (Werner \& Pfleiderer Coperion) with $\mathrm{L} / \mathrm{D}=40$ and diameter $\mathrm{D}=25 \mathrm{~mm}$, at a speed of $250 \mathrm{rpm}$ and temperature $180{ }^{\circ} \mathrm{C}$. Another low MFI polypropylene under trade name 'PP 500P Sabic' was also purchased commercially to compare birefringence for low and high molecular weight PP. In this study the two pure PP and PP/claynanocomposite samples with $0.5 \mathrm{wt} . \%, 1 \mathrm{wt} \%$ and $2 \mathrm{wt} . \%$ clay will be considered as PP $2 \mathrm{MFI}, \mathrm{PP}$ $7 \mathrm{MFI}$, PPNC $0.5 \%$, PPNC $1 \%$ and PPNC $2 \%$ respectively (Table 1 ).

Table 1. Properties of Polymer Samples

\begin{tabular}{|c|c|c|}
\hline Polymer & $\begin{array}{c}\text { Melt Flow Index } \\
\mathbf{2 3 0} \mathbf{C} / \mathbf{2 . 1 6 K g} \\
{[\mathbf{g} / \mathbf{1 0} \mathbf{~ m i n}]}\end{array}$ & $\begin{array}{c}\text { PP/PP-g-MA/nano clay } \\
\text { [wt. } \% \text { ] }\end{array}$ \\
\hline PP 2MFI & 2.22 & $100 / 0 / 0$ \\
\hline PP 7MFI & 7.32 & $100 / 0 / 0$ \\
\hline PPNC 1\% & 9.4 & $98.25 / 0.75 / 1$ \\
\hline PPNC 2\% & 10.4 & $96.5 / 1.5 / 2$ \\
\hline PPNC 4\% & 11.4 & $93 / 3 / 4$ \\
\hline
\end{tabular}

Characterization. First MFI were found on MFI Machine Zwick (Germany) at standard ASTM D$1238\left(230{ }^{\circ} \mathrm{C} / 2.16 \mathrm{Kg}\right)$ conditions for polypropylene. Then, the filler type and dispersion state were confirmed. The transmittance peaks were observed on the characteristic wavelength region of a clay mineral after Fourier Transform Infrared Spectroscopy (FTIR) (PerkinElmer, Spectrum One) over the wave numbers ranging from 450 to $4000 \mathrm{~cm}^{-1}$ with FR-DTGS detector. The small angle X-Ray scattering spectra were collected at wavelength of $1.542 \mathrm{~A}^{\circ}$ using Hecus (model S3-MICROpix) Austria with $\mathrm{Cu}$ anode for two samples, Cloisite 15 A powder and PPNC 2\%. The generator was operated at $15 \mathrm{KV}$ and $1 \mathrm{~mA}$. The samples were placed at a distance of $254 \mathrm{~mm}$ from the detector for an exposure time $2000 \mathrm{sec}$. The characteristic peak for Cloisite 15 A clay appearing at $2 \theta=$ $2.64^{\circ}$ corresponding to an interlayer spacing of $33.4 \mathrm{~A}^{\circ}$ completely disappeared in PPNC $2 \%$ spectrum, suggesting exfoliated dispersion of the clay. Therefore no stacking of the silicate layers have been observed suggesting a well dispersed layers system within the polymer matrix.

Characterization during Extensional Flow. Pure PP 2MFI, PP 7MFI and its clay nanocomposite in molten condition were passed through a slit die with the purpose of establishing the birefringence pattern. The main advantage of this technique is that flow analysis can be executed without disturbing the original flow. In this study, the birefringence could be captured only for both pure PP and PPNC $0.5 \%$ due to optical transparency issues at higher concentrations of clay. The experimental details are documented below.

Polymer pellets are fed into the feed hopper of single screw extruder along with five band heaters and contractors to maintain the temperature gradient throughout. The melt then flows through linking flanges and crosses a short extension arm at 90 degrees to come into the die block kept at a constant temperature to get the molten polymer at $170^{\circ} \mathrm{C}$. Borosilicate-heat-annealed cutglass windows are used along the die block in order to view the flow field. This flow cell enables light to pass through the flowing material and thus allow us to measure flow birefringence in a given channel of interest. The resultant data is in dark and bright retardation bands and is converted into principal stress differences using a stress optical law [32]. The square shaped die has an aspect ratio $(\mathrm{W} / 2 \mathrm{H})$ of 15 to 1 with dimensions $8 \mathrm{~mm}$ length, $15 \mathrm{~mm}$ width and $1 \mathrm{~mm}$ depth to avoid any third dimensional effects [32]. 
The flow birefringence measurements are performed using an optical set up as shown schematically in (Fig 1). A halogen lamp $(\lambda=656.28 \mathrm{~nm})$ is used as light source, light collimating lenses are used to produce a parallel beam and a digital camera Canon 7D (lens: 50mm, f 1.8) with green light filter to assure light with single wavelength is also included to capture the flow field as black and white fringes. An analyzer and polarizer were crossed at 45 degrees with respect to the slit axis. When monochromatic polarized light is used, white and black bands appear due to interference and the transmitted light consists of bands corresponding to the level of retardation. The other important relation which is helpful to calculate principal stress difference is given below:

$$
\Delta \mathrm{n}=\frac{\mathrm{N} \lambda}{\mathrm{d}}
$$

where $\mathrm{N}$ is called fringe number or fringe order, $\lambda$ wavelength of light, $\mathrm{d}$ thickness of the medium. Using stress optical rule (1) and above equation (3), it is possible to calculate the principal stress difference by estimating birefringence of the melt system. With the help of values of $\mathrm{C}$ given in literature [10], a value of $0.5 \times 10^{-9} \mathrm{~m}^{2} / \mathrm{N}$ for the stress optical coefficient is being used for pure polypropylenes and polypropylene clay nanocomposite at $170^{\circ} \mathrm{C}$ in this study.

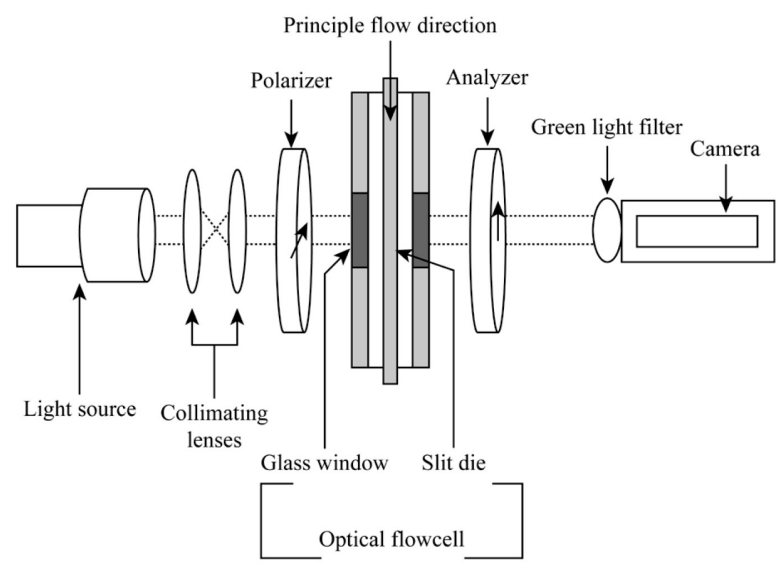

Fig. 1. Optical path to capture flow induced birefringence during elongational flow

Characterization in Simple Shear. The simple shearing experiments are performed using higher clay concentrations i.e. 0.5 wt. \%, 1 wt. \% and 2 wt. \% clay along with pure PP 7MFI. Rheology samples were prepared as round disks of $25 \mathrm{~mm}$ diameter and $1 \mathrm{~mm}$ thick using hot press at a temperature of $190^{\circ} \mathrm{C}$ for 10 minutes. The experiments were carried out under nitrogen environment on MCR 501-Rheometer (Paar Anton, Germany) in the parallel plate geometry with $25 \mathrm{~mm}$ diameter and a gap about $1 \mathrm{~mm}$. The investigations were done under controlled strain measurements. Step strain and stress relaxation measurements after a step strain are performed at 10 $\%, 100 \%, 200 \%$, and $300 \%$ strains at $180{ }^{\circ} \mathrm{C}$; and relaxation modulus (G) was measured with respect to time for all strains. Steady shear viscosity was measured at a range of shear rate from 0.001-100 1/s at $180{ }^{\circ} \mathrm{C}$ for PP 7MFI, PPNC 0.5 \%, PPNC $1 \%$, and PPNC $2 \%$.

\section{Results and Discussion}

Flow Induced Birefringence (Extensional Flow). The fringe profile was also attained for high molecular weight polypropylene having low MFI (PP 2MFI) to confirm chain entanglement effects. Comparisons were discussed for PP 7MFI, its clay nanocomposite PPNC $0.5 \%$ and PP $2 \mathrm{MFI}$ (Fig 2). 


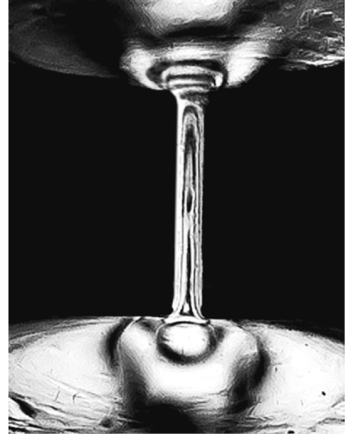

(a)

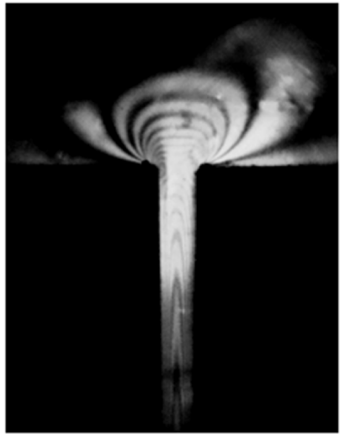

(b)

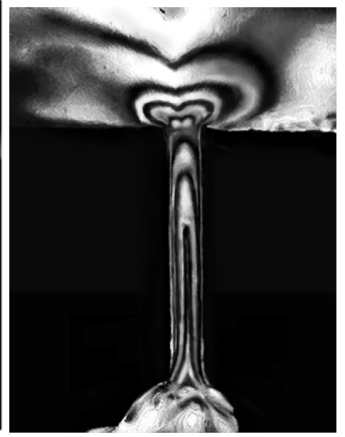

(c)

Fig. 2. Front views captured for PP 7MFI, PP $2 \mathrm{MFI}$ and PPNC $0.5 \%$ melts flowing through the slit die along y-direction at a flow rate $0.55 \mathrm{~g} / \mathrm{sec}(\mathrm{a})(\mathrm{b})$ and (c) respectively at $170^{\circ} \mathrm{C}$

Complexity of the whole flow field was obvious. At a given flow rate the principal stress difference is likely to build up inside the reservoir achieving a maximum before the slit entrance and then decreases along the slit section due to stress relaxation. Appearance of residual stress and further stress relaxation in the slit section was also observed. From the birefringence patterns, it could be concluded that the dominant direction of orientation of molecules within the entrance region of the duct was along the stream lines of the flow. To understand the development pattern of fringes, the analysis should start from zero flow rate which is gradually increased and observed. The order is started from zero, which appeared black in white light and remained stationary with rotating polarizers [33]. Consequently, an estimation of stresses could be possible at varying locations along the stream line where dark bands were observed by finding their fringe order. From these observations it was seen that the fringes originate from the corners of the slit entrance and shift towards the center where fringes of same retardation join each other. In literature [34-36], it has also been reported that the highest stress level is attained at the slit entrance connecting with the maximum fringe order, particularly when the melt element approaches at the contraction from the upstream reservoir; it experiences considerable stretching along the flow direction resulting a maximum of flow birefringence or principal stress difference at the entrance of die. Inside the slit section the fringes tend to become parallel to the die wall and as melt moves further away from the entry section. This indicates that a time-independent steady state stress level exists in the flow near the wall [37-39].

Comparing the Fig. 2, the fringe pattern was appeared to be different in shape only for clay nanocomposite. PP 2MFI had more number of small fringes, which were closely placed in each photograph as compared to PP 7MFI (Fig. 2a \& b). Hence it may be concluded that a polymer with similar molecular structure but with different molecular weight would behave differently at similar deformation conditions. By the throat of the slit section the fringes converge and PP 2MFI showed greater concentration of fringes therefore the overall maximum stress was also greater. The longer chains of high molecular weight polymer may entangle during the melt flow resulting enhanced strain hardening. It was understandable that the rise in molecular weight influenced the flow behavior which was obvious in the observed and measured stress patterns [35, 36]. While comparing fringe profile of pure PP 7MFI with its $0.5 \%$ clay nanocomposite (Fig. 2a, 2c), the discrepancy of the fringe patterns was apparent. In case of PPNC $0.5 \%$, the fringe outline changed from semi circular shape to large $\mathrm{W}$ shape having larger shoulders locating on a distant position. The photograph at similar flow rate explains that the number of fringes (i.e., maximum stress buildup) was identical in both cases, but the appearance of fringes was entirely different. The shoulders of the principal stress difference appearing in the die land for PPNC $0.5 \%$ reflected the slow stress relaxation in the downstream section and a reduction in the principal stress difference along the centerline. Hence the flow was relatively more viscoelastic for clay nanocomposite than for the pure polypropylene, attributed to the presence of silicate layers even at very low concentration. The presence of clay layers, developed solid like structure within the molten polymer causing highly oriented stress field which was quite different from those obtained for PP 2MFI 
(Fig 2). Hence it could not be attributed to chains entanglement as for PP 2MFI, but due to perpendicular layer alignment along the flow direction [19].

Comparisons of flow pattern could also be shown by a plot of principal stress difference obtained through stress optical rule equation (1) and equation (3) using $\mathrm{C}=0.5 \times 10^{-9} \mathrm{~m}^{2} / \mathrm{N}$ for stress optical coefficient at $170^{\circ} \mathrm{C}$ for pure polypropylenes and polypropylene clay nanocomposite with respect to the position along the stream line at same flow rate (Fig 3).

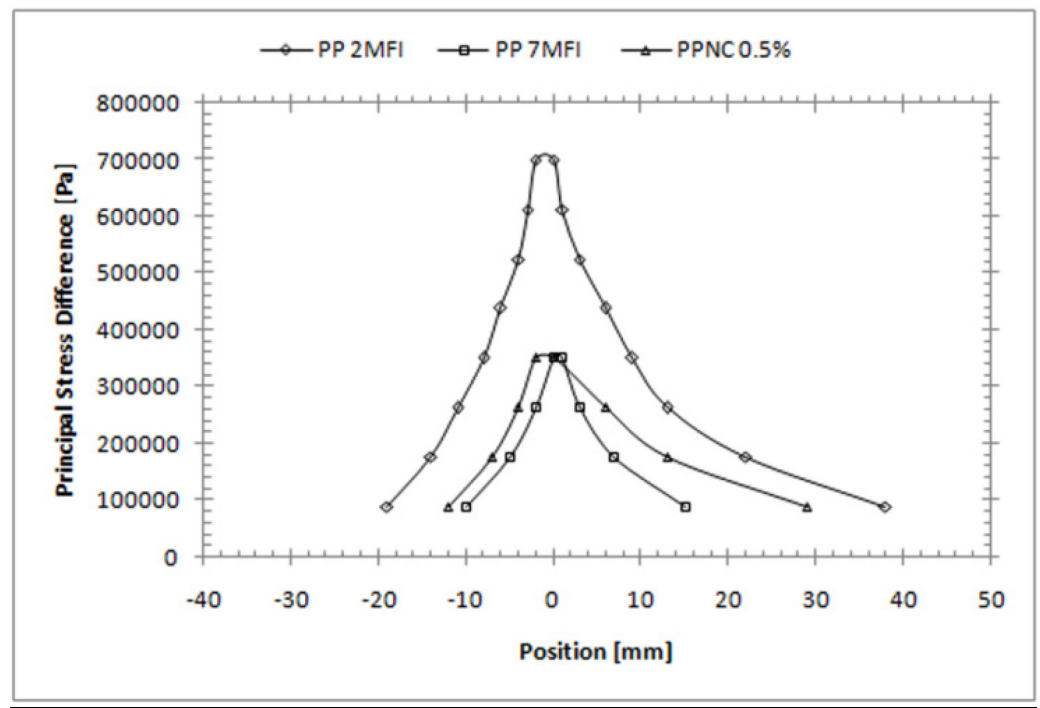

Fig. 3. Using stress optical rule equation (1) and equation (3), at $\mathrm{C}=0.5 \times 10^{-9} \mathrm{~m}^{2} / \mathrm{N}$ for the stress optical coefficient at $170^{\circ} \mathrm{C}$ for $\mathrm{PP}$ 2MFI, PP 7MFI and PPNC $0.5 \%$ principal stress difference as a function of position along centerline of the slit at flow rate $0.55 \mathrm{~g} / \mathrm{sec}$

For flexible homopolymer melts, the stress optical rule is almost universally valid [40]. Values of $\mathrm{C}$ were found to be independent of molecular weight, molecular weight distribution and shear rate; however, it depends on the identity of the monomer unit and also slightly on temperature and optical wavelength [13]. The values of stress optical coefficient for melts and solutions can be found [32, 40, 41]. A plot of entry principal stress difference with respect to position at the same flow rate showed that high molecular weight polypropylene possessed higher stresses at the entry region than low molecular weight polypropylene (Fig 3). While entering the slit polymer chains experienced much greater deformations than those in the upstream region and this region was dominated by the magnitude of short time relaxation modulus. As shown in Fig. 3, the principal stress difference level was same at the slit entrance for both pure PP and its clay nanocomposite, but before the entrance and within the slit it was slightly higher for clay nanocomposite. It means that the pure PP chains were relaxed more in the slit section as compared to clay confined polymer chains of PPNC $0.5 \%$. It was also confirmed by the profile of fringes appeared in the photographs for clay nanocomposite, the $\mathrm{W}$ shape fringes pointed towards additional viscoelastic nature for this sample. It has been reported that these shapes attribute a non-monotonic birefringence difference between the centerline and die walls resulting in a high level of elasticity [10, 42]. Presence of birefringence is an indicative of strain hardening for all the samples studied. It is also an indicative of chain orientation and time-strain separable relaxation modulus [26]. Although, similar maximum principal stress difference for PP 7MFI and its clay nanocomposite indicated similar elongational flow strain hardening as reported [17, 19, 43] probably due to very low silicate concentration considered in this work. On the other hand, maximum principal stress difference at the slit entrance increased drastically for PP 2MFI attributing effect of chain entanglements of higher molecular weight polymer. Therefore it can be concluded that smaller amounts of clay responded with delayed chain relaxation during elongations through an abrupt entry flow, while similar strain hardening for pure matrix and PPNC $0.5 \%$ may be attributed towards absence of structural networking at minimum clay concentrations. The presence of enhanced viscoelasticity is due to the interfacial attractions between solid layers and flexible chains. Also perpendicular layer alignment to the flow direction could be predicted during elongational flow causing slower relaxation [19].

The entry principal stress difference (PSD) was plotted against flow rate for all samples (Fig 4); it was depicted that by increasing the flow rate, number of fringes were also increased and as a consequence, more stress magnitudes were calculated at higher melt flows. So it was found that 
entrance principal stress difference was a linear function of flow rate in the region considered. Accordingly the birefringence tends to increase linearly with flow rate. Similar results have been reported for a number of linear and branched polyolefins melt [35, 36, 38, 44, 45]. The PSD was observed to be increased greatly for PP 2MFI, while for PP 7 MFI and its clay nanocomposite the increase was similar and smaller than for PP $2 \mathrm{MFI}$.

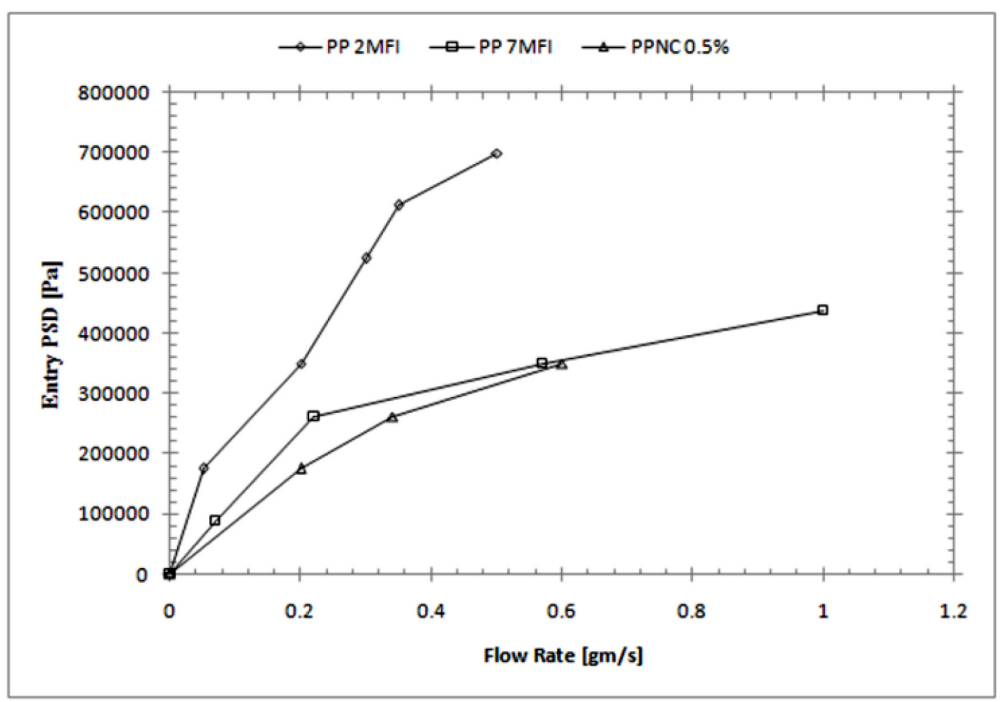

Fig. 4. Principal stress difference at slit entrance as a function of flow rate at $170^{\circ} \mathrm{C}$

Non-Linear Simple Shearing Flow. The ratio of $G(\gamma, t) / G(t)$ provided the damping function $\mathrm{h}(\gamma)$ to evaluate the damping coefficient $\mathrm{k}$ as an exponential fit to shear rate vs $\mathrm{h}(\gamma)$ data using equation (2) for simple shearing flow. Fig 5 has shown a plot of damping function coefficient against clay concentration.

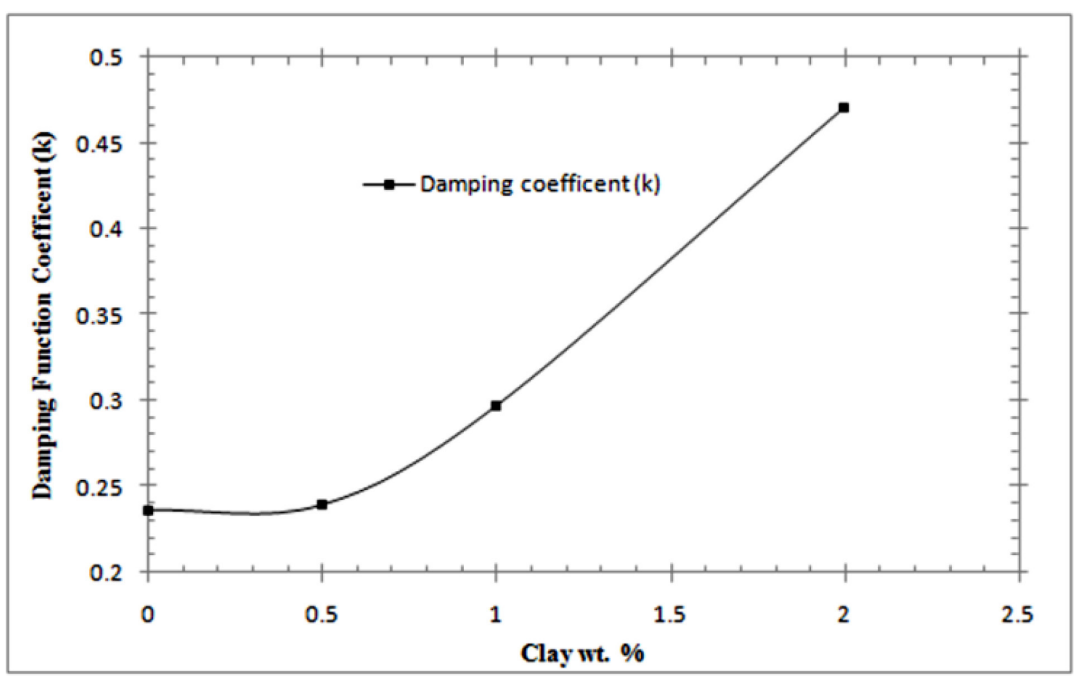

Fig. 5. Damping function coefficient $(\mathrm{k})$ as a function of clay wt.\% obtained from step strain relaxation experiments at $180^{\circ} \mathrm{C}$

In contrast to the extensional flow, the clay tended to depress the damping function, specifically making the nanocomposites more strain softening as compared to the pure PP during shearing flow. Therefore damping coefficient was increased with clay concentration attributing to the better processibility of polypropylene clay nanocomposites as compared with pure polypropylene. The decreased damping function also revealed more strain dependence or less elastic behavior for PMMA and smectite clay nanocomposites due to the alignment of layered structure with the shearing direction [26]. However, the change in damping coefficient was significant only for PPNC $1 \%$ and PPNC $2 \%$, whereas it was comparable for the other two samples. Therefore, the lowest concentration of silicate layers could not affect the damping coefficient greatly and revealed identical strain dependence as the pure polyolefin. It has been reported in literature that the damping functions for the clay nanocomposites are comparable to the damping function of pure polymer at low volume fractions, however, it would be decreased by increasing the layers volume fraction [25]. 
The results for steady shear viscosity are shown in Fig. 6 . The viscosity of pure polypropylene was higher than $0.5 \mathrm{wt} \% \%$ and $1 \mathrm{wt} . \% \mathrm{PP} /$ clay-nanocomposites, whereas it was lesser than PPNC $2 \%$. Presence of compatibilizer makes the nanocomposite low viscous at low shear rates as as compared to the pure PP. It has an effect of dilution on polypropylene viscosity, as reported [46], but presence of clay with compatibilizer increases the viscosity because the oxygen of clay silicate introduces strong hydrogen bonding with the polar functional group of PP-g-MA. As observed in $2 \%$ sample, the different viscosity pattern for $0.5 \%$ and $1 \%$ was attributed to the smaller clay concentration, and to second time melt compounding of PPNC2\% with pure PP in order to obtain $0.5 \%$ and $1 \%$ samples that may cause some chain length degradation. The MFI results (Table 1) showed the same trend in flowing conditions that pure PP was more viscous as compared to all nanocomposite samples, but these conditions were comparable with high shear rate region of viscosity. It has been discussed that the lower amounts of clay layers within the host melt can enhance the flow-ability of the melt due to favorable orientations with the flow direction, but at higher concentrations when establishment of a physical network between the layers has been attained, the melt fluidity of the nanocomposites is lowered by the clay loadings, identically to other inorganic filler based polymer composites [43]. Whereas viscosity of all samples converges at higher shear rates, and onset of shear thinning behavior was started earlier in case of clay nanocomposite samples because of parallel orientation of clay layers, that was attributed to the pseudo-solid like behavior with presence of yield stress; it has also been reported before for polypropylene and its clay nanocomposite [47].

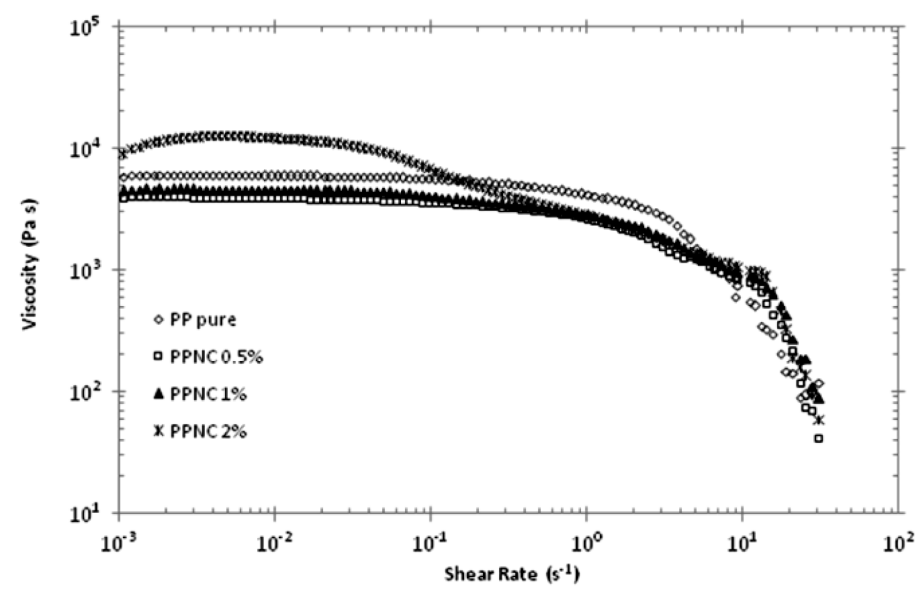

Fig. 6. Comparison of steady shear viscosity as a function of shear rate at $180^{\circ} \mathrm{C}$ for pure polypropylene with its clay nanocomposites is shown where the shear thinning behavior starts earlier for nanocomposites

Comparing simple shearing flow with the extensional flow, it may be concluded that simple shearing flows could alter the viscoelastic properties of polymer clay nanocomposites only at sufficient clay layers, while at minimum concentrations, the layers would respond to similar viscoelastic properties. However during extension even small clay concentrations were responsible for enhanced chain stretching and orientation, causing more viscoelastic flow for a polymer/claynanocomposite.

\section{Conclusions}

The rheological investigations during extensional and simple shearing explained the time-strain separable rheology for pure polyolefin and its clay-nanocomposite. The melt flow behavior of polymer chains was affected due to the presence of nano filler during both cases. However extensional flow was more sensitive even at smaller concentrations of clay as revealed by flow birefringence pattern for polyolefin clay nanocomposite. Additional viscoelastic response suggested perpendicular clay layer alignment with shear direction. Exceptional strain hardening as observed for the high molecular weight polyolefin was not found for low molecular weight polyolefin claynanocomposite at the slit entrance. The entry principal stress difference was also a linear function of flow rate in the region considered. On the other hand, during simple shear silicate layers alignment 
on application of high shear rates could facilitate the industrial processing of the polymer, attributed to increasing damping function coefficient with filler concentrations. The effects were more obvious at higher filler concentrations found in commercial polymer clay-nanocomposites. Also the onset of shear thinning steady shear viscosity started earlier in case of clay nanocomposite samples highlighted the favorable orientation of clay layers attributing to the pseudo-solid like behavior as well as parallel layer alignment along the flow. Hence different filler orientations were found for different melt flow behavior.

\section{Acknowledgment}

We acknowledge the Higher Education Commission Pakistan for funding this research under "Indigenous PhD 5000 Fellowship No. 085-12279-PS5-228" and "International Research Support Initiative Program (PIN: IRSIP 22 Ps 17).

\section{References}

[1] B. Momani, M. Sen, M. Endoh, X. Wang, T. Koga, H.H. Winter, Temperature dependent intercalation and self exfoliation of clay/polymer nanocomposite, Polymer., 93 (2016) 204-212.

[2] M. Nematollahi, A. Jalali-Arani, K. Golzar, Organoclay maleated natural rubber nanocomposite. Prediction of abrasion and mechanical properties by artificial neural network and adaptive neurofuzzy inference, Appl. Clay Sci., 97-98 (2014) 187-199.

[3] M.Z. Iqbal, A.A. Abdala, V. Mittal, S.n. Seifert, A.M. Herring, M.W. Liberatore, Processable conductive graphene/polyethylene nanocomposites: Effects of graphene dispersion and polyethylene blending with oxidized polyethylene on rheology and microstructure, Polymer., 98 (2016) 143-155.

[4] M. Ganjaee Sari, B. Ramezanzadeh, A.S. Pakdel, M. Shahbazi, A physico-mechanical investigation of a novel hyperbranched polymer-modified clay/epoxy nanocomposite coating, Prog. Org Coat., 99 (2016) 263-273.

[5] M. Kotal, A.K. Bhowmick, Polymer nanocomposites from modified clays: Recent advances and challenges, Prog. Polym Sci., 51 (2015) 127-187.

[6] S. Sinha Ray, M. Okamoto, Polymer/layered silicate nanocomposites: a review from preparation to processing, Prog. Polym. Sci., 28 (2003) 1539-1641.

[7] M.A. Treece, W. Zhang, R.D. Moffitt, J.P. Oberhauser, Twin-screw extrusion of polypropyleneclay nanocomposites: Influence of masterbatch processing, screw rotation mode, and sequence, Polym. Eng. Sci., 47 (2007) 898-911.

[8] Q.H. Zeng, A.B. Yu, G.Q. Lu, Multiscale modeling and simulation of polymer nanocomposites, Prog. Polym Sci., 33 (2008) 191-269.

[9] G.G. Fuller, Optical rheometry of complex fluids, Oxford University Press, New York, (1995).

[10] R. Muller, B. Vergnes, J.M. Piau, J.F. Agassant, Rheology Series, Elsevier, 1996, pp. 257-284.

[11] H. Janeschitz-Kriegl, Polymer melt rheology and flow birefringence, Springer Science \& Business Media, 2012.

[12] A.S. Lodge, Variation of flow birefringence with stress, Nat., 176 (1955) 838-839.

[13] C.W. Macosko, Rheology, Principles, Measurements and Applications, VCH Publishers Inc., New York, 1994.

[14] K.E. Strawhecker, E. Manias, Structure and properties of poly (vinyl alcohol)/Na+ montmorillonite nanocomposites, Chem Mater., 12 (2000) 2943-2949. 
[15] S. Suin, S. Maiti, N.K. Shrivastava, B.B. Khatua, Mechanically improved and optically transparent polycarbonate/clay nanocomposites using phosphonium modified organoclay, Mater. Desig., 54 (2014) 553-563.

[16] S. Suin, N.K. Shrivastava, S. Maiti, B.B. Khatua, Phosphonium modified organoclay as potential nanofiller for the development of exfoliated and optically transparent polycarbonate/clay nanocomposites: Preparation and characterizations, Eur. Poly. J., 49 (2013) 49-60.

[17] S.H. Lee, J.R. Youn, Properties of polypropylene/layered-silicate nanocomposites and meltspun fibers, J. Appl. Polym. Sci., 109 (2008) 1221-1231.

[18] S. Hwan Lee, E. Cho, J. Ryoun Youn, Rheological behavior of polypropylene/layered silicate nanocomposites prepared by melt compounding in shear and elongational flows, J. Appl Polym Sci., 103 (2007) 3506-3515.

[19] M. Okamoto, P.H. Nam, P. Maiti, T. Kotaka, N. Hasegawa, A. Usuki, A house of cards structure in polypropylene/clay nanocomposites under elongational flow, Nano Lett., 1 (2001) 295298.

[20] R. Krishnamoorti, J. Ren, A.S. Silva, Shear response of layered silicate nanocomposites, The J. Chem. Phy., 114 (2001) 4968-4973.

[21] Y. Zhong, Z. Zhu, S.-Q. Wang, Synthesis and rheological properties of polystyrene/layered silicate nanocomposite, Polymer., 46 (2005) 3006-3013.

[22] S. Pujari, L. Dougherty, C. Mobuchon, P. Carreau, M.-C. Heuzey, W. Burghardt, X-ray scattering measurements of particle orientation in a sheared polymer/clay dispersion, Rheolog. Acta., 50 (2011) 3-16.

[23] T. Aubry, T. Razafinimaro, P. Mederic, Rheological investigation of the melt state elastic and yield properties of a polyamide-12 layered silicate nanocomposite, J. Rheol., 49 (2005) 425-440.

[24] T. Takahashi, J.i. Takimoto, K. Koyama, Uniaxial elongational viscosity of various molten polymer composites, Polym Composite., 20 (1999) 357-366.

[25] V.H. Rolon-Garrido, M.H. Wagner, The damping function in rheology, Rheologi. Acta., 48 (2009) 245-284.

[26] R. Kotsilkova, Rheology-structure relationship of polymer/layered silicate hybrids, Mech. Time-Depend. Mater., 6 (2002) 283-300.

[27] A.C. Papanastasiou, L.E. Scriven, C.W. Macosko, An integral constitutive equation for mixed flows: viscoelastic characterization, J. Rheol., 27 (1983) 387-410.

[28] J. Ren, R. Krishnamoorti, Nonlinear viscoelastic properties of layered-silicate-based intercalated nanocomposites, Macromolec., 36 (2003) 4443-4451.

[29] M.H. Wagner, Zur Netzwerktheorie von Polymer-Schmelzen, Rheologica Acta. 18 (1979) 3350 .

[30] M.R. Mackley, R.T.J. Marshall, J.B.A.F. Smeulders, F.D. Zhao, The rheological characterization of polymeric and colloidal fluids, Chem.l Eng. Sci., 49 (1994) 2551-2565.

[31] J. D. Shaw, M. Jaison, E. Amj, Nonlinear viscoelastic properties, J. Rheol., 23 (2010) 241249.

[32] J.L.S. Wales, Delft University of Technology, Delft, Netherlands, 1976.

[33] S.T.E. Aldhouse, M.R. Mackley, I.P.T. Moore, Experimental and linear viscoelastic stress distribution measurements of high density polyethylene flowing into and within a slit, J. Non-Newt. Fluid Mech., 21 (1986) 359-376. 
[34] H.J. Park, D.G. Kiriakidis, E. Mitsoulis, K.J. Lee, Birefringence studies in die flows of an HDPE melt, J. Rheol., 36 (1992) 1563-1583.

[35] M.T. Martyn, C. Nakason, P.D. Coates, Flow visualisation of polymer melts in abrupt contraction extrusion dies: quantification of melt recirculation and flow patterns, J. Non-Newt. Fluid Mech., 91 (2000) 109-122.

[36] M.T. Martyn, C. Nakason, P.D. Coates, Stress measurements for contraction flows of viscoelastic polymer melts, J. Non-Newt. Fluid Mech., 91 (2000) 123-142.

[37] R. Ahmed, Fitzwilliam College, University of Cambridge, England, 1993.

[38] L. Robert, B. Vergnes, Y. Demay, Flow birefringence study of the stick-slip instability during extrusion of high-density polyethylenes, J. Non-Newt. Fluid Mech., 112 (2003) 27-42.

[39] D.R. Arda, M.R. Mackley, The effect of die exit curvature, die surface roughness and a fluoropolymer additive on sharkskin extrusion instabilities in polyethylene processing, J. NonNewt. Fluid Mech., 126 (2005) 47-61.

[40] H. Janeschitz-Kriegl, Polymer Melt Rheology and Flow Birefringence, Springer-Verlag, Berlin Heidelberg New York 1983.

[41] R. Muller, B. Vergnes, Validity of the stress optical law and application of birefringence to polymer complex flows, Rheol. Ser., 5 (1996) 257-284.

[42] N. Checker, M.R. Mackley, D.W. Mead, On the flow of molten polymer into, within and out of ducts, Phil. Trans. R. Soc. Lond. A., 308 (1983) 451-477.

[43] K. Wang, S. Liang, J. Deng, H. Yang, Q. Zhang, Q. Fu, X. Dong, D. Wang, C.C. Han, The role of clay network on macromolecular chain mobility and relaxation in isotactic polypropylene/organoclay nanocomposites, Polymer., 47 (2006) 7131-7144.

[44] Y. Goutille, J.-C. Majeste, J.-F.o. Tassin, J. Guillet, Molecular structure and gross melt fracture triggering, J. Non-Newt. Fluid Mech., 111 (2003) 175-198.

[45] M.W. Collis, M.R. Mackley, The melt processing of monodisperse and polydisperse polystyrene melts within a slit entry and exit flow, J. Non-Newt. Fluid Mech., 128 (2005) 29-41.

[46] W. Lertwimolnun, B. Vergnes, Influence of compatibilizer and processing conditions on the dispersion of nanoclay in a polypropylene matrix, Polymer., 46 (2005) 3462-3471.

[47] S.Y. Gu, J. Ren, Q.F. Wang, Rheology of poly (propylene)/clay nanocomposites, J. Appl. Polym., Sci. 91 (2004) 2427-2434. 